\title{
O trabalho de cuidar de pacientes terminais com câncer
}

\author{
The task of caring for terminally ill cancer patients
}

Nádia Roberta Chaves Kappaun ${ }^{1}$

Carlos Minayo Gomez ${ }^{2}$

${ }^{1}$ Divisão de Saúde do Trabalhador, Instituto Nacional de Câncer José Alencar Gomes da Silva. R. Marques de Pombal 125/ $12^{\circ}$, Centro. 20.230-240 Rio de Janeiro RJ. nadiafst@gmail.com

2 Escola Nacional de Saúde Pública, Fiocruz.

\begin{abstract}
This is a study conducted in the palliative care unit of the INCA National Cancer Institute, in an attempt to understand the nature of the work and its effects on the health of the professionals. A qualitative approach is adopted, based on participant observation and semi-structured interviews with professionals from the hospital. Most of the professionals are female and were unaware of the concept of palliative care when they started their careers in the Unit. Teamwork is highly valued by the professionals who involve the families in the care actions and motivate the participation of patients and relatives in decision-making. However, these workers experience high emotional stress due to their involvement in the suffering of patients and families. They are also exposed to considerable physical stress caused by the intense demand of the daily routine and the dependence of the majority of patients. The study revealed that there are many professionals on leave of absence due to musculoskeletal problems and psychiatric disorders. There is a pressing need for health support programs for these professionals and awareness of daily care measures for their own health. However, their suggestions for improvement of working and health conditions are merely passed on to be implemented by the institutions themselves.
\end{abstract}

Key words Health and work, Palliative care, Health care
Resumo Estudo realizado na unidade de cuidados paliativos do Instituto Nacional de Câncer José Alencar Gomes da Silva (INCA), com o objetivo de compreender as características do trabalho e suas repercussões na saúde dos profissionais. Adotou-se abordagem de cunho qualitativo, com base em observação participante e entrevistas individuais semiestruturadas com profissionais do setor de internação hospitalar. A maioria das profissionais é do sexo feminino e desconhecia a proposta dos cuidados paliativos quando começou a trabalhar na unidade. O trabalho em equipe é muito valorizado pelas profissionais que envolvem a família nas ações de cuidado e incentivam a participação de pacientes e familiares na tomada de decisões. As trabalhadoras vivenciam elevado desgaste emocional ao conviverem com o sofrimento de pacientes e familiares e desgaste físico pela grande demanda provocada pela rotina cotidiana e pela dependência da maioria dos pacientes: é elevado o número de licenças que recebem por doenças osteomusculares e psiquiátricas. Há necessidade de programas destinados a promover a saúde dessas profissionais e que estejam alertas a cuidados cotidianos para evitarem os desgastes. Entretanto, suas sugestões de melhoria das condições de trabalho e saúde foram enviadas apenas à instituição para que tome providências.

Palavras-chave Saúde e trabalho, Cuidados paliativos, Cuidado em saúde 


\section{Introdução}

Os cuidados paliativos têm como objetivo principal promover a qualidade de vida do paciente até a sua morte, para que possa usufruir ao máximo de sua capacidade física e mental ${ }^{1}$. Nesse cuidado a doentes terminais, ressalta-se a necessidade de aliviar seu sofrimento, mas também manter uma atitude de afeto e escuta, lembrando que têm sentimentos, desejos, opiniões e o direito de serem ouvidos. Porém, quando a morte é considerada um tabu pelos próprios cuidadores, eles podem impedir, com a sua ansiedade, que o doente divida sua dor com eles ${ }^{2}$. Para que o trabalho de cuidado seja efetivo, os profissionais precisam se preparar e compreender seus próprios sentimentos, de modo a conseguir dar atenção necessária aos pacientes entendendo seu contexto social ${ }^{3}$ e ajudando-os a se preparar para a morte ${ }^{4}$.

A equipe de uma unidade de cuidados paliativos é formada por médicos, enfermeiros e outros profissionais, como fisioterapeutas, psicólogos, assistentes sociais e capelães ${ }^{5}$. É importante valorizar as habilidades que os diversos profissionais têm para atenuar o sofrimento que se vive nesse ambiente, sobretudo, contribuindo na discussão de casos, o que, em geral, se bem conduzido, promove o êxito do tratamento e o crescimento profissional de todos ${ }^{6}$. Os profissionais da saúde, em geral, encontram muita dificuldade em mudar uma visão exclusivamente curativa e em reconhecer quando o paciente se encontra em estado fatal ${ }^{7}$.

A filosofia dos cuidados paliativos propõe estabelecer uma relação entre profissionais, pacientes e familiares em que as decisões são compartilhadas, cada um com seu papel, mas diferente do modelo habitual de assistência à saúde ${ }^{8}$. O destaque dado à relação entre equipe de saúde e usuários configura um tipo de estratégia de coprodução, ou seja, o envolvimento conjunto nas operações para prover cuidados e a emergência do usuário como ator pertinente na gestão de muitas das atividades?.

Neste estudo, buscou-se compreender como que vem sendo realizado o trabalho em cuidados paliativos e quais as suas repercussões na saúde dos profissionais desse setor.

\section{Metodologia}

Apresenta-se o resultado de um estudo de cunho qualitativo $^{10,11}$, com base em observação partici- pante e entrevistas individuais semiestruturadas. A observação ocorreu de forma livre, sem roteiro prévio e as situações consideradas mais significativas para a finalidade do estudo foram registradas em diário de campo. As entrevistas foram realizadas seguindo um roteiro orientador com uma questão inicial para desencadear a conversa: "Fala-me sobre os seus sentimentos em lidar com esse perfil de paciente".

O local do estudo foi o setor de internação hospitalar da unidade de cuidados paliativos, Hospital do Câncer IV - HC IV, do Instituto Nacional de Câncer José Alencar Gomes da Silva - INCA do Rio de Janeiro. Esse setor se destina a pacientes que precisam estabilizar o quadro clínico antes de retornarem a seu domicílio. Durante o período de internação, a presença de acompanhantes é fundamental e esses são treinados para que sigam os procedimentos de cuidado ao paciente em sua casa ${ }^{12}$.

$\mathrm{Na}$ internação hospitalar, há 138 profissionais da assistência direta ao paciente, sendo a maioria formada pela equipe de enfermagem que é fixa por andar. Além dessas profissionais, a Unidade conta com quatro médicas, quatro assistentes sociais, duas fisioterapeutas, três psicólogas e sete nutricionistas. Em cada um dos quatro andares há um auxiliar de serviços gerais e existe um serviço de maqueiros que serve a todos no caso de remoção de pacientes ou transporte de material para exames.

O trabalho de campo se iniciou com a observação participante. Os processos de trabalho dos diferentes profissionais foram acompanhados, bem como os intervalos e os momentos de confraternização da equipe de saúde. Posteriormente se iniciaram as entrevistas, quando a presença da pesquisadora já se havia tornado habitual para as trabalhadoras. O convite para essa "conversa com finalidade" 10,11 foi feito nos respectivos turnos de trabalho. Na medida em que concordavam e tinham disponibilidade, ocorriam as entrevistas, gravadas com consentimento das interlocutoras e numa sala reservada no andar onde trabalham. A maioria se mostrou receptiva, e as que marcaram horário e não compareceram o fizeram por contingência de suas atividades, na maioria das vezes imprevistas. Foram ouvidas 14 profissionais de todas as categorias de assistência direta: enfermeiras, técnicas de enfermagem, assistentes sociais, fisioterapeutas, psicólogas, médicas e nutricionistas. Embora de diferentes categorias, por fazerem parte de um coletivo que trabalha em grupo, suas falas coincidiram em relação aos temas estudados. 
No percurso de interpretação dos dados, procurou-se encontrar a lógica interna dos fatos, relatos e observações, situando-os no contexto dos sujeitos e assim, promover a interpretação dos fatos ${ }^{10,11,13}$. Os passos seguidos foram: leitura compreensiva do material selecionado; identificação e ordenamento das categorias empíricas e elaboração de uma síntese interpretativa, tendo como base as referências sobre o tema e o conteúdo das falas e observações ${ }^{13}$.

Ressaltaram do estudo os seguintes temas: a trajetória profissional em cuidados paliativos, o sentido do trabalho e questões relativas ao processo de trabalho, a importância do trabalho em equipe, a relação com o paciente e a família e os sentimentos gerados ao presenciar a morte de pacientes. Estes serão analisados e discutidos a seguir.

A pesquisa foi submetida e aprovada pelos comitês de ética das instituições proponente e participante.

\section{Resultados e Discussão}

\section{Cuidados paliativos: produção e coprodução do cuidado}

Parte-se do pressuposto de que a abordagem em cuidados paliativos requer a constituição de uma equipe multiprofissional ${ }^{5,14} \mathrm{e}$ a participação ativa do paciente e de seus familiares ${ }^{1}$. E como essas atividades são desempenhadas comumente por pessoas do gênero feminino ${ }^{15}$, utilizam-se nesse gênero as palavras que se referem aos profissionais da unidade estudada.

Logo ao início das entrevistas, várias profissionais relataram tanto o desafio que supõe atuar em cuidados paliativos destacando suas características especificas, como a ausência de uma formação prévia para atuar nessa área: quando eu ouvi falar que viria para o HC IV, entrei na internet e fui descobrir o que era o HC IV (Entrevistada 1). Que o trabalho é diferenciado, até porque nós não temos formação pra trabalhar em cuidados paliativos (Entrevistada 13). A formação, varias comentaram, vai-se adquirindo durante a própria prestação dos cuidados desde o primeiro momento de inserção na Unidade. Outras profissionais referiram que conheceram a filosofia dos cuidados paliativos durante a graduação, a residência, a especialização ou mesmo através de colegas. A chegada à unidade de cuidados paliativos ocorreu, da parte de algumas por opção e, de outras, por processo seletivo.
Essa "formação em serviço" tem possibilitado o desenvolvimento de competências para atuar nessa proposta para a qual não houve formação prévia, nem foi exigido que o profissional tivesse um perfil adequado para o trabalho. No entanto, algumas profissionais consideram que: em cuidados paliativos você tem que gostar do que faz. Como te falei no início, tem que ter o perfil (Entrevistada 8).

Nesse processo de formação em serviço afloram conflitos entre o que se aprendeu durante a formação profissional acadêmica e as exigências do cuidado a esse tipo de paciente, assim como entre as propostas formais e as possibilidades concretas de atuação da instituição. Nesse sentido, uma profissional expressa essa tensão ao comentar as restrições havidas na sua atuação ao não poder criar ou propor aos pacientes algo diferente do estabelecido: Agora, assim, muitas vezes aqui, eu me sinto uma [atendente] de luxo, por aí perguntando o que a pessoa quer [...] Eu não vejo, assim, muito crescimento pra [minha área de formação] tá atuando, não sei se muitas vezes pela politica do hospital (Entrevistada 7).

As profissionais referem também que inicialmente se sentiam mais mobilizadas com as experiências no trabalho, mas foram criando estratégias para lidarem melhor com isso e apontam a necessidade de suporte principalmente nesse momento ${ }^{16}$ : No início foi bastante chocante. Depois, a gente vai lidando com a dinâmica, vai aprendendo, vai desenvolvendo e caminha (Entrevistada 11). A atuação desencadeia reflexões sobre a própria vida e a forma de conduzi-la: E se a gente tentar pensar nisso um pouquinho todo dia, vai tentar deixar tudo sempre organizado (Entrevistada 6).

Sobre o caráter desse trabalho dizem: é estressante, é cansativo, mas é valoroso como é caso da Entrevistada 1. Outras ressaltam a importância do seu reconhecimento do cuidado que prestam pelas próprias trabalhadoras e pelos pacientes e familiares: ele consegue reconhecer que ele está sendo acolhido, consegue reconhecer que tem alguém ali por ele (Entrevistada 6). Porém, a expectativa de valorização também se revela como um anseio: $O$ que o profissional daqui espera? $O$ reconhecimento da chefia, do próprio grupo (Entrevistada 13).

As faces desse trabalho, sua dureza e seu valor, são assinaladas como fonte de desgaste, mas também de satisfação: ajudar o familiar, ajudar o paciente a ter menos sintomas em relação ao processo é muito interessante e é apaixonante (Entrevistada 5). 
Contudo, as exigências das atividades de cuidado também requerem a implantação de algumas mudanças como a redução da jornada semanal - que atualmente é de 40 horas - e o aumento na quantidade de profissionais. O reduzido número destas exige um maior acúmulo de trabalho: mas claro que tem as dificuldades do diaa-dia [...] de ter déficit de profissionais (Entrevistada 4), ou ainda a dificuldade em participar de todas as atividades da equipe por ter que cobrir a escassez de servidoras: hoje em dia não tem como acompanhar os rounds, por conta de estar aqui, ali, ter que resolver uma questão aqui, outra lá (Entrevistada 5).

Ainda assim, o trabalho em equipe é ressaltado como essencial para que as necessidades do paciente e das famílias sejam melhor atendidas, pois não tem como a gente achar que um único ser consegue centralizar vários olhares para uma pessoa com tanta complexidade (Entrevistada 6). As profissionais se orgulham, por isso, da convergência de opinião que cada avaliação e impressão profissional tem: nossa avaliação aqui tem um peso quando uma conduta é traçada (Entrevistada 10), ressaltando a participação de todos nas decisões: é muito bacana porque todo mundo tem a sua voz (Entrevistada 1).

Destaca-se, no conjunto, a atuação das médicas que compartilham com a equipe algumas decisões como a alta ou a revisão dos horários de uma medicação. Porém, algumas profissionais lamentam a ausência de participação das técnicas de enfermagem nos espaços institucionalizados: eles [técnicos de enfermagem] têm que ser valorizados, eles têm que ter voz, participar dos rounds em equipe (Entrevistada 2). Comentam que existe uma relação mais estreita do enfermeiro com os técnicos (Entrevistada 13) e, portanto, seria necessário incluí-los nas discussões da equipe de saúde como um todo, de modo a se conseguir uma verdadeira atuação de caráter multiprofissional na gestão do trabalho ${ }^{17}$.

Essa gestão compartilhada entre os profissionais, com a participação de pacientes e familiares, própria da coprodução estabelecida na atuação em cuidados paliativos, se dá não só quando se deseja promover a autonomia dos usuários, mas também quando condutas são realizadas de acordo com a demanda do paciente ou de um familiar, como é o caso de ouvir um desabafo, dar uma explicação, ou ainda, negociar uma decisão.

Para alcançar tais objetivos, presume-se que haja um diálogo aberto, uma comunicação adequada que esclareça as possibilidades ${ }^{18}$ de respei- tar os desejos do paciente. Porém, existem resistências e conflitos surgidos no trato com pacientes que insistem em recusar a proposta da equipe: São coisas que você não vai entender nunca, porque os seus conceitos são conceitos diferentes dos dele. Então é um trabalho que você desconstrói, constrói novas coisas em cima (Entrevistada 8).

Apesar da intenção de promover autonomia, por vezes, os próprios usuários desejam absterse e repassam à equipe a responsabilidade por determinadas decisões. Frente a essa contradição entre a proposta da instituição e a dificuldade ou mesmo recusa dos usuários em fazer opções, cabe às profissionais o encargo de lidar com tal lacuna. Frequentemente, elas têm que desenvolver respostas e ações não previstas, que exigem conhecimentos e habilidades.

A relação entre a equipe de saúde e os usuários, também é marcada pela maneira como cada ator vivencia o processo de morrer. As profissionais falam da existência de um "tipo ideal" de acompanhante, que é o participativo, compreensivo, semelhante ao identificado por Menezes ${ }^{8}$, mas também apontam que há aqueles que não compreendem e relutam em aceitar as informações. Por ser esse um período de muita angústia, sofrimento e às vezes de incompreensão da família, a busca por atenção ou a exigência sobre a equipe é intensa. Em diversos momentos da observação, constatou-se que as trabalhadoras precisavam parar o que estavam fazendo para dar atenção aos familiares que questionavam um procedimento ou os cuidados frente ao estado do paciente. $\mathrm{Na}$ pesquisa se presenciaram cenas em que muitos familiares pediam que a alta fosse dada somente quando o paciente estivesse "melhorzinho", demonstrando falta de compreensão do estado avançado da doença. Isso exigia que a profissional falasse claramente sobre a situação terminal do doente e acolhesse a angústia dos parentes.

Considerando que, em cuidados paliativos, a família participa das ações de cuidado ao paciente, mas também recebe cuidados da equipe de saúde ${ }^{1,14,19}$, observou-se que as profissionais, muitas vezes, se veem obrigadas a atender excesso de demandas dos parentes, o que lhes é gerador de desgaste. Uma fala é exemplar sobre tal situação: aqui a gente não atende 12 pacientes, mas 24 (Entrevistada 5), ao se referir à lotação da enfermaria. Apesar de nela estarem 12 pacientes, o cuidado se direcionava também aos 12 acompanhantes. Situações como essa merecem ser consideradas no dimensionamento do número adequado de profissionais. 


\section{Cuidados paliativos \\ e a coprodução do adeus}

O ideal seria que a morte ocorresse em domicílio com a pessoa rodeada de seus familiares. Mas como lembra uma profissional, esse é o ideal que deveria ser, mas não é (Entrevistada 11). E, por conseguinte, a frequência de óbitos na internação hospitalar é alta: a gente presencia óbitos aqui quase diariamente, quase todo dia pelo menos um paciente. Já teve dias de ter quatro óbitos (Entrevistada 4). E isso supõe que as profissionais devam dar suporte ao paciente, quando esse momento se aproxima e, também à família, durante todo o processo: então, a gente está lidando com a morte a cada cinco minutos (Entrevistada 2).

Em cuidados paliativos o profissional deve reconhecer o estado em que o paciente se encon$\operatorname{tra}^{20}$, o que significa que "morte" e "luto" são vivenciados antes do evento determinado no tempo, durante o período, longo ou breve, do processo de morrer. Nessa situação de trabalho, a imagem antecipada da morte ${ }^{21}$ permeia as relações mantidas com o paciente, pois o paciente nem está entendendo o que está acontecendo, ele está morrendo (Entrevistada 6). Não se vivencia, portanto, apenas o momento da morte ou à frequência com que os óbitos ocorrem, mas todo o sofrimento do paciente e de sua família na busca por tratamento e cura do câncer. A chegada dos usuários aos cuidados paliativos é já o resultado de uma jornada desgastante e um momento no qual se assume a proximidade da morte inevitável, porém geralmente escamoteada durante a maior parte da existência humana.

A vivência das profissionais com o processo de morrer é única, não só porque cada processo é único e imprevisível, como também porque o seu impacto é individual. Aqui nos deparamos com o que a coprodução tem de específico e com o que essa atividade traz de mais particular: o contato com o outro e com a imagem da morte, lembrando ao profissional sua própria finitude. A isso se acresce a presença dos familiares que exigem atenção, determinando que a condução da atividade de cuidados nessas circunstâncias constitua uma "carga de trabalho"22, imensurável, imprevisível, porém inegável.

Com a proximidade do óbito, além do contato com o paciente, assume destaque a relação entre a equipe e a família. Os familiares devem ser preparados para o acontecimento, por meio da comunicação da proximidade da morte, pela flexibilização de algumas regras, como é o caso do horário de visita. Inicia-se também a assis- tência ao luto, quando se informa sobre aspectos burocráticos, como os referentes ao sepultamento e à solicitação de benefício, entre outros. É também quando se pode identificar a aceitação, ou não, da morte pela família.

A permanência ao lado do paciente ou da família no momento da morte é comentada por poucas profissionais, tanto nas entrevistas, quanto nas conversas informais, porém o conteúdo das falas dos que se expressaram trouxe grande riqueza à reflexão. Um dos relatos é de uma técnica de enfermagem sobre a experiência de dar suporte a um paciente com hemorragia que veio a falecer e, ao presenciar a angústia dele tentando evitar sujar o quarto, segurando uma cuba e sobre a quantidade de sangue expelida: me senti ganhando um dinheiro sujo, evidenciando a existência de situações imprevisíveis e impactantes, para as quais não se pode treinar e muito menos determinar o que se deve fazer.

No momento da morte, a família recebe atenção especial: no momento do óbito, a gente fala assim 'não precisa mais pressa'. A abordagem agora é a família (Entrevistada 13). E as profissionais voltam seu foco para a maneira como os parentes vivenciam esse momento, ajustando o trabalho e a expressão de seus sentimentos de acordo com a situação: se você não tem estrutura, a família tem muito menos! Quando a família não aceita, você tem que passar por cima das [próprias] dificuldades, para mostrar para ela que era o momento, que tinha que acontecer (Entrevistada 4). Após o óbito, a família tem a oportunidade de permanecer ao lado do corpo e se despedir, sendo depois direcionada pela equipe para uma sala em que recebe suporte dos profissionais.

Quando a família sai do quarto, as técnicas de enfermagem entram para realizar o que se chama de "preparo do corpo". Esse procedimento é destinado a cuidados antes que o corpo se torne rígido e deve ser realizado para que possa ser retirado do quarto. Nessa hora, se faz o tamponamento dos orifícios, o fechamento dos olhos e a amarração das duas mãos, à altura do abdômen, e dos dois pés. Apesar da habilidade com que as técnicas de enfermagem realizam esse procedimento, é um momento de tal solenidade que a comunicação se direciona exclusivamente para a atividade.

A observação e a fala das técnicas revelam a continuidade da presença física e simbólica do paciente, pois há preocupações como colocar um esparadrapo onde a pele estava lesionada ou acondicionar o envelope onde o corpo será guardado, de modo a facilitar que a família possa 
abri-lo e visualizar o seu rosto, caso deseje se despedir mais uma vez, pronunciando palavras e rezando orações: Eu acredito que tem alguma coisa, algum envolvimento espiritual ali presente, a gente só não tem capacidade para compreender, mas deve haver.

Essas atitudes demonstram que não é um trabalho realizado sobre um objeto, mas sobre um sujeito real e simbólico, uma vez que o contato com aquele paciente foi permeado por trocas, confissões e até desejos que ainda estão ali, como uma lembrança vívida para as técnicas e para a família: no preparo do corpo, eu nem sei muito que pensar. Eu reconheço que ali tem um corpo que representa pra uma família, que representou um pai, uma mãe, uma pessoa que fez parte da vida dela. Então tem que ser tratado com muito respeito.

Após a despedida, as profissionais apontam algo que consideram importante para a conclusão do processo de cuidado: o atendimento pósóbito. Esse atendimento pode ser realizado através de contato telefônico, quando a equipe busca conhecer como a família está realizando o período de luto, disponibilizando-se a receber os familiares no hospital, caso desejem. Também o contato pode ser agendado pela própria família, que às vezes ainda precisa de um documento ou deseja rever a equipe.

Apesar de sua importância, percebe-se que o pós-óbito não é realizado com frequência e nem da forma prevista, já que habitualmente a rotina assistencial não permite aos profissionais assumir esse compromisso. No entanto, podem aparecer, sem agenciamento prévio, familiares para solicitar alguma demanda que certamente é atendida.

\section{Atenção à sobrecarga do trabalho}

No trabalho hospitalar em cuidados paliativos, as profissionais convivem com a solidão, o medo da loucura e do adoecimento físico pela mobilização emocional e física que as histórias dos pacientes suscitam mesmo fora do ambiente hospitalar ${ }^{20}$. Grande carga emocional e desgaste subsequente são repercussões geradas no desempenho de incumbências relacionadas ao sofrimento e à morte: Por tudo isso que a gente vive, por todo esse envolvimento, o profissional tem uma hora que não aguenta também (Entrevistada 4).

Ao se referirem aos impactos físicos e mentais de sua atividade, utilizam com frequência o termo "desgaste" que, a rigor, representaria a perda, parcial ou efetiva, da capacidade biológica ou psíquica. Entre os elementos de desgaste físico, foram apontados problemas frequentes na co- luna vertebral, questões relativas à estrutura do trabalho como insuficiência de macas elétricas, características dos pacientes internados (que, geralmente, são dependentes totais de cuidados e são pesados), necessidade de cobrir a ausência de colegas e número reduzido de profissionais: Atualmente o que está acontecendo e que está influenciando é que tem poucos profissionais, tem alguns de licença. Então, isso sobrecarrega um pouco (Entrevistada 14).

Quanto ao desgaste emocional, cabe esclarecer que, quando a morte é percebida como etapa da vida, o que mais afeta às trabalhadoras deixa de ser a morte e passa a ser o sofrimento dos pacientes diante da dor ${ }^{8}$ a a gente fica muito sobrecarregada, tem um desgaste não só físico, mas também emocional bastante significativo, porque você se envolve não só com o paciente, mas também com a família (Entrevistada 4). O sofrimento relacionado à situação da família é maior quando os profissionais convivem com pacientes jovens, com pessoas que deixarão filhos pequenos: assusta um pouco porque inevitavelmente você transfere para você, para sua família (Entrevistada 8). Ou seja, para as profissionais, lidar com o processo de morrer é lidar com o sofrimento e com a dor não só do paciente, mas com a dor das perdas vivenciadas por elas e sua família; sofrimento que elas reatualizam cotidianamente, tomam para si e levam consigo - Então, queira ou não, a gente acaba absorvendo essa... essa carga (Entrevistada 11).

Entendendo que a morte do outro traz à lembrança a própria ${ }^{21}$, percebeu-se também que existe por parte de algumas a negação da própria morte, tomando distância da situação alheia: $e$ u acho que a própria experiência me ajudou a entender que a morte é sempre do outro, a morte nunca é a sua morte, essa experiência a gente não tem (Entrevistada 10), falando da necessidade do distanciamento e do não envolvimento como condição de sobrevivência: a morte está ali e faz parte de você. Mas que isso não te afete de forma a levar para tua vida o que vive aqui (Entrevistada 8).

Os efeitos das cargas de trabalho e do desgaste podem ser verificados ao se observar o alto índice de licenças: nunca se teve um absenteísmo tão alto como está tendo nesse momento (Entrevistada 10). Essa profissional assinala a premente necessidade de se oferecer às profissionais algum tipo de suporte ou programa de atenção a sua saúde: a dureza do trabalho nos aponta essa necessidade, porque por mais que a gente goste [é muito doloroso e desgastante]. Pois isso não me isenta do sofrimento, um sofrimento que é inerente ao próprio processo de trabalho (Entrevistada 10). 
Os dados do setor de saúde da instituição na unidade estudada corroboram a importância de adotar medidas para melhorar esse quadro. A média mensal de afastamentos para tratamento da própria saúde é de 31 profissionais, por um período aproximado de 12 dias, o que corresponde a quase 369 dias não trabalhados pela equipe, por mês.

Não foi possível conhecer os agravos relativos aos afastamentos, mas segundo afirmam as profissionais: a gente vê muita licença não só por questões físicas, mas também psiquiátricas (Entrevistada 4). Entretanto, poderiam ser feitas alguma previsões a partir de estudos como o realizado sobre adoecimentos e afastamentos de trabalhadores do setor hospitalar no qual foram identificadas as lesões por esforços repetitivos (LER), os distúrbios osteomusculares relacionados ao trabalho (DORT), o estresse e a síndrome de burnout, como sendo os principais agravos de ordem física ou mental ${ }^{23}$.

As profissionais manifestaram sugestões e expectativas de que sejam implantadas ações de suporte e apoio à saúde. Em relação à carga física de trabalho, sugeriram ginástica laboral ou alongamentos antes de iniciarem suas atividades. Foi lembrado que uma fisioterapeuta inicialmente passava em cada setor, convocando a equipe para realizar a ginástica laboral no andar. Porém, quando isso se estendeu para outro andar, não foi mais possível manter a regularidade dos exercícios.

Sobre o sofrimento inerente ao processo de trabalho, as profissionais enfatizaram: a gente trabalha com um processo que já é difícil, nós somos $38^{\circ}$ lugar, um dos países com piores condições de morte no mundo (Entrevistada 2). Apontaram também alguns conflitos havidos quando os desejos do paciente se confrontam com os da família ou ainda com a proposta da equipe ${ }^{24}$. Relataram principalmente, a necessidade de se preparar previamente o profissional que vai atuar com tais cuidados, não apenas do ponto de vista o técnico, mas emocional também: que requer muito preparo e não é só técnico, é emocional (Entrevistada 2). Várias citaram que precisam desenvolver habilidades e competências que não são transmitidas em treinamentos, nem são alcançadas por prescrições. E descrevem como uma estratégia importante para o enfrentamento do cotidiano: a gente [precisa] trabalhar a gente primeiro, para depois estar trabalhar com eles [doentes e familiares] (Entrevistada 8).

$\mathrm{Na}$ Unidade estudada houve já alguns grupos de reflexão e foram oferecidos cursos - um sobre tanatologia - considerados pelos profissi- onais muito oportunos para refletirem sobre sua atuação. Citaram também uma reunião, que é conduzida pelo capelão da Unidade, denominada sessão de espiritualidade, como um momento para compartilharem suas angústias e se recobrarem para continuar o trabalho: nossa, que bom, como eu sinto falta de um momento que a gente consiga dar uma recarregada, agora bola pra frente, e vamos seguir nossas coisas! (Entrevistada 6). As profissionais citaram também estratégias pessoais para se recarregarem como é o caso a seguir: às vezes eu me sinto tão cansada que eu desço fico dois minutinhos no sol e subo meio que para recarregar as energias (Entrevistada 1).

Como sugestão de suporte psicológico, as profissionais indicaram a necessidade de contar com uma psicóloga que ficaria num espaço reservado para atendimento individual quando elas considerassem necessário e a rotina do trabalho o permitisse. Apontaram também a necessidade de ter um período de pausa na rotina que vivenciam como uma estratégia de cuidado de si: ter um momento de descontração. Que a gente lida com a morte aqui o tempo todo, então, não vejo nenhuma atividade voltada para isso. Digamos até meia hora de lazer, uma coisa de descontração, até mesmo, sei lá, uma missa, um culto, alguma coisa que te desse conforto também (Entrevistada 7).

Outra proposta sugerida foi a criação de um espaço de participação obrigatória: Eu acho que esse lugar deveria ser obrigatório, esse lugar que quem cuida do outro pudesse buscar reservas. Então a gente precisa de um espaço que seja reconhecidamente um espaço cedido, não barganhado, mas dado: esse espaço é de vocês, ponto! (Entrevistada 10).

\section{Considerações finais}

O estudo revelou que a filosofia dos cuidados paliativos era desconhecida para a maioria das profissionais até chegarem à unidade estudada, $\mathrm{o}$ que denota a ausência de relevância em todos os âmbitos da sociedade com questões como a morte e a "boa morte", embora esse seja o evento mais certo de acontecer com todos os seres vivos ${ }^{8}$.

O fato de parte das profissionais desconhecerem a filosofia e as práticas de cuidados paliativos até chegarem à unidade é consequência tanto do fato de que a morte seja um tabu ${ }^{25}$ como da ausência do tema na formação profissional. A fala dos profissionais, no entanto, evidencia a necessidade de sua preparação prévia à incorporação nesse setor de trabalho. Essa formação, segundo a opinião das entrevistadas, deveria in- 
cluir, além dos conhecimentos técnicos sobre esse tipo de cuidado, informações sobre as competências e habilidades a serem aperfeiçoadas no cotidiano de trabalho ${ }^{26}$.

A coprodução do cuidado, com a participação ativa do paciente e de sua família, representa uma mudança de modelo assistencial, trazendo exigências para as profissionais, não só no sentido de se abrirem à negociação com os usuários, mas também para que saibam gerir os conflitos frequentemente vivenciados no diálogo com pacientes e familiares.

É importante lembrar que o lugar da família nesse contexto assistencial tem duas vertentes: a de prestadora de cuidados ao paciente e a de receptora de cuidados da equipe. Como necessitada de atenção, ela costuma gerar uma sobrecarga ao trabalho dos profissionais, que por sua vez precisam de suporte e respaldo. É muito importante que, dentro do contexto e sempre que possível, a família seja tratada como parceira nos cuidados que seu ente querido requer ${ }^{27}$.
Apesar de ser um trabalho extenuante e que atua com os limites da vida e as formas como os seres humanos enfrentam a doença e a morte, existe uma forte identificação dos profissionais com o paciente e a família com quem compartilham o sofrimento. No mesmo sentido, embora o conflito entre posições sociais, opiniões e decisões seja fonte potencial de desgaste para os profissionais, através do trabalho eles conseguem reconhecimento e satisfação e suas falas refletem isso.

Ao terminar, ressalta-se que os profissionais que atuam em cuidados paliativos precisam ser cuidados, precisam de uma jornada de trabalho menos intensa, de apoio psicológico e de momentos de descontração e mesmo de recreação. Alguns falam até de necessidade de apoio espiritual. Espera-se que este estudo possa contribuir para que sejam tomadas iniciativas institucionais com vistas à melhoria da gestão e da organização do trabalho que possibilitem reduzir a intensidade da rotina assistencial e a participação da equipe em espaços destinados a discutir e revisar suas práticas.

\section{Colaboradores}

NRC Kappaun e CM Gómez participaram igualmente de todas as etapas de elaboração do artigo. 


\section{Referências}

1. Saunders C. Foreword. In: Doyle D, Hanks G, Cherny N, Calman K, editors. Oxford textbook of palliative medicine. $3^{a}$ Edição. New York: Oxford University Press; 2004. p. v-ix.

2. Kübler-Roos E. Sobre a Morte e o Morrer. São Paulo: Martins Fontes; 2008.

3. Ajemian I, Mount BM. The adult pacient: cultural considerations in palliative care. In: Saunders C, Summers DH, Teller N, editors. Hospice: the living idea. London: Edward Arnold; 1981. p. 19-31.

4. Menezes RA. Tecnologia e "morte natural": o morrer na contemporaneidade. Physis 2003; 13(2):129147.

5. Radbruch L, Payne S. White Paper on standards and norms for hospice and palliative care in Europe: part 2 - Recommendations from the European Association for Palliative Care. European Journal of Palliative Care 2010; 17(1):22-33.

6. Marcucci FCI. O papel da fisioterapia nos cuidados paliativos a pacientes com câncer. Rev. bras. cancerol. 2005; 51(1):67-77.

7. Mccoughlan M. A necessidade de cuidados paliativos. O Mundo da Saúde 2003; 27(1):6-14.

8. Menezes RA. Em busca da boa morte: antropologia dos cuidados paliativos. Rio de Janeiro: Editoras Garamond, Fiocruz; 2004.

9. Salerno MS. A seu serviço: interrogações sobre o conceito, os modelos de produção e o trabalho em atividades de serviços. In: Salerno MS, organizador. Relação de serviço: produção e avaliação. São Paulo: SENAC São Paulo; 2001.p. 9-22.

10. Minayo MCS. O desafio do conhecimento: pesquisa qualitativa em saúde. 12a Edição. São Paulo: Editora Hucitec; 2010.

11. Minayo MCS. Análise qualitativa: teoria, passos e fidedignidade. Cien Saude Colet 2012; 17(3):621-626.

12. Brasil. Ministério da Saúde (MS). Instituto Nacional de Câncer. Conheça o Hospital do Câncer IV 2009. 2a Edição. Rio de Janeiro: INCA; 2009.

13. Gomes R. Análise e interpretação de dados de pesquisa qualitativa. In: Minayo MCS, organizadora. Pesquisa Social: teoria, método e criatividade. 32a Edição. Petrópolis: Vozes; 2012. p. 79-108.

14. West T. Multidisciplinary working. In: Saunders C, editor. Hospice and Palliative Care: an interdisciplinary approach. London: Edward Arnold; 1990. p. 313.

15. Araújo TM, Rotenberg L. Relações de gênero no trabalho em saúde: a divisão sexual do trabalho e a saúde dos trabalhadores. In: Assunção AA, Brito J, organizadores. Trabalhar na saúde: experiências cotidianas e desafios para a gestão do trabalho e do emprego. Rio de Janeiro: Editora Fiocruz; 2011. p. 45-65.
16. Loiselle CG, Sterling MM. Views on death and dying among health care workers in an Indian cancer care hospice: balancing individual and collective perspectives. Palliat Med 2010; 26(3):250-256.

17. Matos E. A contribuição da prática interdisciplinar na construção de novas formas de organização do trabalho em saúde [tese]. Florianópolis: Universidade Federal de Santa Catarina; 2006.

18. Ribeiro DC. Autonomia: viver a própria vida e morrer a própria morte. Cad. Saude Publica 2006; 22(8):1749-1754.

19. O’Brien T, Monroe B. Twenty-four hours before and after death. In: Saunders C, editor. Hospice and Palliative Care: an interdisciplinary approach. London: Edward Arnold; 1990. p. 46-53.

20. Simoni M, Santos ML. Considerações sobre cuidado paliativo e trabalho hospitalar: uma abordagem plural sobre o processo de trabalho de enfermagem. Psicol. USP 2003; 4(2):169-194.

21. Elias N. A solidão dos moribundos. Rio de Janeiro: Jorge Zahar; 2001.

22. Laurell AC, Noriega M. Para o estudo da saúde na sua relação com o processo de produção. In: Laurell AC, Noriega M. Processo de saúde e produção e saúde. São Paulo: Hucitec; 1989. p. 99-144.

23. Sala A, Parreira SMCO. O Trabalho no Setor Hospitalar: adoecimento e afastamentos por motivos de saúde. In: Assunção AA, Brito J, organizadores. Trabalhar na saúde: experiências cotidianas e desafios para a gestão do trabalho e do emprego. Rio de Janeiro: Editora Fiocruz; 2011. p.151-170.

24. Floriani CA, Schramm FR. Cuidados paliativos: interfaces, conflitos e necessidades. Cien Saude Colet 2008; 13(Supl. 2):2123-2132.

25. Rodrigues JC. O tabu da morte. Rio de Janeiro: Editora Fiocruz; 2010.

26. Zarifian P. Objetivo Competência: por uma nova lógica. São Paulo: Atlas; 2001.

27. Fratezi FR, Gutierrez BAO. Cuidador familiar do idoso em cuidados paliativos: o processo de morrer no domicílio. Cien Saude Colet 2011; 16(7):32413248.

Artigo apresentado em 30/04/2013

Aprovado em 22/05/2013

Versão final apresentada em 24/05/2013 